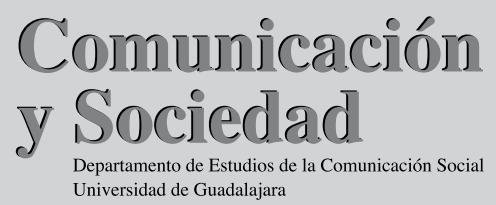

\title{
¿Cómo vemos a nuestros vecinos del norte? Apuntes sobre la representación de San Diego en la prensa de Tijuana
}

\author{
MAGALÍ MURIÁ* Y TEÓFILO CHÁVEZ**
}

Las fuertes contradicciones de la relación bilateral entre México y Estados Unidos son mucho más visibles en la frontera. Esto se observa en el contenido periodístico, que refleja y refuerza imágenes y estereotipos, e influye en como se ve a quienes viven del otro lado de la línea divisoria. Por medio de un análisis de contenido de las noticias, anuncios publicitarios y clasificados del periódico El Mexicano, se busca aquí encontrar algunas pautas para abordar la discusión en torno a la representación de San Diego en la prensa de Tijuana, y sugerir vínculos con tendencias históricas y prácticas culturales presentes en la región.

PALABRAS CLAVE: Frontera MéxicoEstados Unidos, prensa fronteriza, noticias, consumo.
The deep contradictions inherent to the bilateral relationship between Mexico and the United States are even more visible at the border that separates these countries. This may be observed in their journalism, which reflects and reinforces images and stereotypes that have an influence on how those who live on the other side of the border are perceived. Through the analysis of the contents of news pieces, advertisements and classified ads in El Mexicano, we seek for guidelines to discuss the representation of San Diego in the press of Tijuana and to suggest connections with historical trends and current cultural practices in the region.

KEY WORDS: Mexico-United States border, Mexico-United States relationship, border press, news, consumption.

* Universidad Autónoma de Baja California.

Correo electrónico: mmuria@weber.ucsd.edu

** Universidad Autónoma de Baja California.

Correo electrónico apleno@hotmail.com 
México y Estados Unidos son dos naciones adheridas por la inevitable geografía, pero también separadas por una marcada asimetría económica y profundas diferencias culturales. A través de la historia, las relaciones entre los dos países han atravesado por periodos de fricción y armonía relativas, en los cuales es innegable el peso de la prensa y la forma en que esta refleja y refuerza las tensiones y acercamientos que sobrevienen entre aquellos (Bailey citado por Coatsworth y Rico, 1989).

La prensa transmite las imágenes y discursos que prevalecen en la opinión pública, a la vez que los proyecta a la sociedad. Son actores que reproducen los símbolos y significados del sistema cultural en el que se inscriben (Schudson, 1995:18-19), estableciendo con ello un diálogo productivo que contribuye a generar el conocimiento público compartido por los miembros de una nación. En el contexto de la relación México-Estados Unidos, la prensa incide en la construcción de estereotipos que determinan cómo vemos al "otro", de qué forma percibimos las diferencias entre "ellos" y "nosotros", y en qué términos establecemos nuestra relación con quienes viven al otro lado de la línea divisoria.

En las ciudades fronterizas de ambos países, la interacción adquiere una dimensión desconocida para los habitantes de otras regiones, pues en aquellas se viven, más intensamente que en ningún otro lado, las constantes paradojas y contradicciones de la convivencia. En este espacio geográfico los dos mundos se abrazan y chocan a la vez, lo que obliga a sus residentes a hacer converger en la intimidad de su vida cotidiana lenguas distintas, costumbres diferentes y formas culturales contradictorias. Esto ha generado hipótesis relativas al posible nacimiento de una tercera nación, que no es ni americana ni mexicana, sino el resultado de la combinación de ambas. Al respecto, la revista Time se ocupó, en junio del 2001, del tema de la frontera y lo tituló Welcome to Amexica, haciendo referencia a la fusión de culturas que existe en esta región.

En este escenario, no falta quien se ha dado a la tarea de estudiar cómo viven los fronterizos, la paradójica relación entre México y Estados Unidos, y de qué forma construyen y representan cultural y respectivamente el lado opuesto de la frontera. Del lado mexicano, la hipótesis de la tercera nación se pone en tela de juicio con el trabajo de autores que destacan el hecho de que la conciencia nacional entre los 
fronterizos es muy sólida, precisamente por estar expuestos al "otro" de forma cotidiana (Bustamante, 1989). Del lado estadounidense, la idea también se ha cuestionado en serio y se han realizado estudios para indagar sobre la imagen que se tiene en San Diego, de Tijuana. Joseph Nevins hace referencia a los resultados de una encuesta realizada en el condado de San Diego en 1991, de acuerdo con la cual la mayoría de los sandieguinos se oponía a fortalecer los vínculos entre San Diego y Tijuana, y 54\% de los entrevistados declaró nunca haber visitado esta ciudad (Nevins, 2002:82).

También se han elaborado disecciones sobre los mecanismos a través de los cuales se fue estructurando, en ambos lados, la representación imaginaria de Tijuana como ciudad del vicio y perdición, y se ha aclarado que dicha imagen se construye en gran medida a partir de la mirada y necesidades de los norteamericanos (Félix, 2003.) Sin embargo, son pocos los esfuerzos dedicados a explorar cómo se representan estas imágenes en la prensa. Al respecto, Ruth Wallin elaboró un análisis comparativo sobre las representaciones fronterizas en periódicos de San Diego y Tijuana, consistente en examinar fotografías de la frontera y deducir si la presentan como un puente que une y comunica, o una barrera que aisla y separa (Wallin, 2003.)

Con pocas excepciones, como la del estudio de Wallin, no existen esfuerzos sistemáticos por averiguar qué visión presenta de San Diego la prensa tijuanense, y cómo refleja esta el lugar que ocupa dicha ciudad en el mapa cultural de sus pobladores. En este contexto, se busca aportar, aquí, elementos para el estudio de las representaciones culturales que se construyen en la prensa tijuanense sobre lo que comúnmente se conoce como "el otro lado". ¿Qué imagen refleja la prensa de Tijuana sobre San Diego? ¿Qué tanta atención se presta a los sucesos que ocurren en su vecina del norte? ¿Qué tipo de interacción con "el otro lado" sugiere la prensa tijuanense?

\section{Metodología}

Para responder a estas preguntas hicimos un análisis de contenido de 46 ejemplares del periódico El Mexicano. Con el objetivo de obtener una visión amplia de largo plazo y para evitar riesgos de errores sistemáti- 
cos en el análisis de la imagen que proyectó de San Diego esta publicación tijuanense, se escogió al azar un ejemplar por año, iniciando con la primera edición de octubre de 1959, y hasta el 2005.

El estudio se hizo separando en distintos niveles de análisis cada ejemplar, las secciones y las notas. En lo que se refiere a los ejemplares, se identificaron elementos de tipo general, tales como cambios en la organización del periódico, aparición o desaparición de secciones específicas, y se llevó a cabo una contabilización del número de notas en sus respectivas clasificaciones. En el caso de las secciones, realizamos un análisis cuantitativo de las noticias regionales, nacionales, internacionales, deportes, nota roja, sociales, clasificados, cultural y la publicidad, más secciones eventuales desaparecidas con el paso de los años.

Finalmente, en lo que toca a las noticias, elaboramos un análisis cuantitativo examinando el tipo de nota y el tema con que se relacionaba (política, cultura, economía, etcétera), los actores involucrados, la imagen de San Diego o Tijuana que se presentaba, en qué parte del periódico se encontraba (primera página o interiores) y la relevancia de ellas (local, nacional, internacional). Asimismo, se efectuó un análisis cualitativo de algunas notas de interés especial, en particular aquellas que estuvieran relacionadas con cuestiones de interacción fronteriza, que sirvió para relacionar los resultados del análisis con prácticas culturales y tendencias de la vida cotidiana presentes en la región, así como los distintos momentos de la relación bilateral entre México y Estados Unidos con los que coincidió su aparición.

De los clasificados y la publicidad sólo se analizaron los que tuvieran su origen en San Diego o indicaran una transacción transfronteriza, como, por ejemplo, cuando aparecían anuncios clasificados que solicitaran personal para trabajar en San Diego (de niñera, en tiendas, hoteles), o publicidad que estuviera dirigida al público de Tijuana, como tiendas de calzado y ropa, o remates de autos usados.

\section{EL CASO DEL PERIÓDICO EL MEXICANO}

El periódico El Mexicano nació el 29 de octubre de 1959 y es, desde entonces, uno de los medios impresos más representativos de la zona. Cuenta con tres ediciones distintas que publica en las ciudades de 
Tijuana, Mexicali y Ensenada. Contiene secciones de temas variados, como noticias locales, nacionales, internacionales, deportes, espectáculos, sociales, cultura, clasificados, nota roja, economía, y otras eventuales, como ciencia, computación, turismo y ecología. En sus inicios constaba de unas diez páginas, pero con el paso del tiempo fue aumentando hasta consolidarse como una de las principales fuentes de información en la ciudad.

El Mexicano apareció aproximadamente seis años después de que Baja California se convirtiera en estado de la república mexicana, con el objetivo explícito de integrar los municipios que lo conforman y unirlos a la cultura nacional (Trujillo, 2000:265). La idea era reforzar la identidad de los bajacalifornianos, para que la región se convirtiese en un dique frente a la cultura estadounidense (idem).

A lo largo de su historia, El Mexicano ha debido hacer converger esta inclinación nacionalista con el contexto fronterizo, y presentar un contenido que cumpla con el imperativo de fortalecer los vínculos con el resto del país y a la vez resultar atractivo para el público local. En lo que toca a la organización general del periódico, la cobertura de noticias y la publicación de anuncios publicitarios, la forma en que se ha cumplido con este doble propósito, resulta indicativa de la serie de complejidades y ambivalencias propias de la región fronteriza, que destacan entre el público tijuanense con respecto a la relación con Estados Unidos y el resto de México.

\section{EL ÁMBITO LOCAL O LA SECCIÓN INTERNACIONAL: ¿EN DÓNDE SE SITÚA SAN DIEGO?}

A lo largo de su existencia, El Mexicano ha ensayado formas distintas de clasificar las notas provenientes de San Diego. Las secciones que presentan noticias sobre esta ciudad han aparecido y desaparecido en diferentes formas, extensiones y secciones del periódico. Esta indecisión refleja la compleja y ambivalente relación que sostienen los tijuanenses con su ciudad vecina.

Si se busca a San Diego en el mapa, queda claro que se trata de una población adyacente al lado norte de Tijuana, pero separada de ella por la línea internacional. Incluso hay quien considera que ambas 
poblaciones constituyen un solo cuerpo urbano dividido por la frontera (Herzog, 1990.) Sin embargo, este hecho no facilita el trabajo de categorizar esta población en alguna sección específica del diario. ¿Cuál es el espacio correcto para ubicar las noticias relacionadas con San Diego, la sección metropolitana o las notas internacionales? ¿Es mejor colocarlo en la primera plana o atribuirle una sección separada? ¿Lo asignamos junto a otras ciudades de Estados Unidos o lo incorporamos en las noticias locales?

En la primera emisión del diario existía una sección escrita en inglés denominada "English Section". Era de tamaño reducido y sólo apareció durante un par de meses. En ella se informaba sobre sucesos relevantes en Estados Unidos. Para diciembre del mismo año apareció la sección "De la vida americana", la cual también trataba información sobre el vecino país del norte. A diferencia de la anterior, dicha sección estaba escrita en español y las notas provenían de agencias noticiosas estadounidenses. Sin embargo, al igual que su predecesora, duró pocos meses.

En noviembre de 1960 apareció otra sección del mismo estilo titulada "Sección de Los Ángeles", que se concentraba en noticias provenientes de Los Ángeles, California y sus alrededores. Abarcaba una página entera y, a diferencia de las anteriores, era de mayor tamaño, pero dejó de aparecer para septiembre de 1961. En 1962 surgió una pequeña sección de práctica del idioma inglés, que con el paso del tiempo desapareció, para reaparecer más adelante, pues en la actualidad se sigue hallando una sección similar en las páginas del periódico.

En 1980 surge una sección de San Diego la cual desaparece al año siguiente. Más de una década más tarde, en 1992 se exhibe una columna titulada "Desde San Diego". En ella se comentaban sucesos políticos, económicos y culturales de la ciudad. Esta columna se eliminó dos años después y las notas de San Diego comenzaron a publicarse en la sección en la que estaban las noticias estatales y regionales. Más adelante, en 1998, surgió de nuevo la columna "Desde San Diego", misma que desapareció para el año 2000. Finalmente, a partir del 2002 comenzó a publicarse la sección "San Diego California", la cual sigue apareciendo en la actualidad. En ella se comentan los sucesos relevantes de esa ciudad, relacionados con cuestiones políticas, sociales y de interés general, principalmente. Este apartado abarca dos páginas del diario. 
El enfoque especial con que se trata a San Diego, apartándolo de la sección internacional y ubicándolo en el ámbito regional, la representa como parte de los alrededores de Tijuana, al igual que otras poblaciones cercanas. De hecho el periódico cuenta con secciones similares de las ciudades de Tecate y Rosarito, las cuales presentan el mismo formato que la de San Diego. En este sentido, se reconoce que no se puede separar ambas ciudades de acuerdo a criterios legales y políticos estrictos, y que San Diego forma una parte intrínseca de la vida cotidiana de los tijuanenses, pero pese a su cercanía geográfica, no es adecuado considerarlo como una continuación de Tijuana. De esta forma queda claro también que con la intensa interacción fronteriza que tiene lugar entre ambas poblaciones es necesario mantener un contacto informativo.

De acuerdo con Michael Schudson, las noticias se producen de acuerdo a patrones de trabajo, supuestos y significados que se encuentran imbuidos en un sistema cultural (1995:13-14). En este caso los cambios, al situar las noticias provenientes de San Diego en el periódico El Mexicano, coinciden con los supuestos ambivalentes de territorio y espacio que predominan entre los tijuanenses al respecto de la localización exacta de su ciudad vecina, pues el "otro lado" se ubica tan cerca y tan lejos como lo determinen una amalgama de factores simultáneos y contradictorios, difíciles de definir en forma contundente (Duarte, 2001.) Hay una diferencia notoria en la apreciación de los que cruzan la frontera diariamente para estudiar o trabajar, hacer compras o visitar parientes, de la que tienen quienes pierden la vida en su intento por acceder sin autorización al territorio norteamericano.

Asimismo, es muy probable que con el paso de los años se haya identificado la ubicación del público consumidor de El Mexicano en el interior de Estados Unidos, y se haya actuado, en consecuencia, para decidir la importancia de la sección y el idioma en que se configuraría la publicación. La pequeña columna de enseñanza del idioma inglés editada actualmente es un ejemplo del interés del periódico por atender la relación binacional que innegablemente existe entre ambas ciudades, pues San Diego es un mercado atractivo para El Mexicano, que de hecho cuenta con oficinas de ventas en esta ciudad. La gente que convive en ambos lados de la frontera necesita un espacio en el cual mantenerse informada. 


\section{LA DIMENSIÓN TRANSNACIONAL.}

CONTENIDO Y ORIGEN

DE LAS NOTICIAS DE EL MEXICANO

De acuerdo con William Gamson, la prensa transmite en sus mensajes valores específicos y proporciona a los lectores imágenes para interpretar el mundo. En este proceso, la proximidad de los temas que aparecen en los medios masivos de comunicación, y su importancia para la vida cotidiana de las personas tiene relación con la resonancia que estos adquieren en el discurso público (1992:125.) En otras palabras, la prensa define su contenido en respuesta a las percepciones del público, a la vez que determina la importancia que temas diversos adquirirán en la esfera pública.

En este sentido, es indicativa la poca atención que parece prestar $E l$ Mexicano a temas relacionados con San Diego, pues apenas $0.76 \%$ del contenido total corresponde a noticias procedentes de esta ciudad. De 46 ejemplares revisados, solamente 9 presentaron información referente a San Diego y en ninguna edición se encontraron más de 10 notas. Pese a su carácter de publicación fronteriza, El Mexicano presenta más información sobre Estados Unidos en general que la proveniente de San Diego. Las notas originadas en este país representan 7.19\% del total. Asimismo, $65.2 \%$ de los ejemplares tienen alguna nota de carácter binacional, es decir, notas de interés tanto para México como para Estados Unidos, como pueden ser migración, narcotráfico y otro temas de agenda compartida. La mayoría de los ejemplares que contenían este tipo de noticias presentaban entre una y cinco notas binacionales. Solamente un ejemplar tuvo más de cinco notas de este tipo. En lo que corresponde a otras zonas no fronterizas, $43.14 \%$ de las notas se originaron en otras partes de México y $18.20 \%$ en el resto del mundo (ver cuadro 1 ).

Cada tema que aparece en los medios de comunicación refleja un discurso público específico y responde a "un cuerpo particular de ideas y símbolos que se usan en los foros públicos para construir significados en torno a ellos" (ibid.:24.) Dichos cuerpos de ideas también se denominan marcos y constituyen uno de los mecanismos más importantes mediante los cuales los periodistas se convierten en productores de discurso. En este sentido, la prensa construye marcos en torno a los temas 


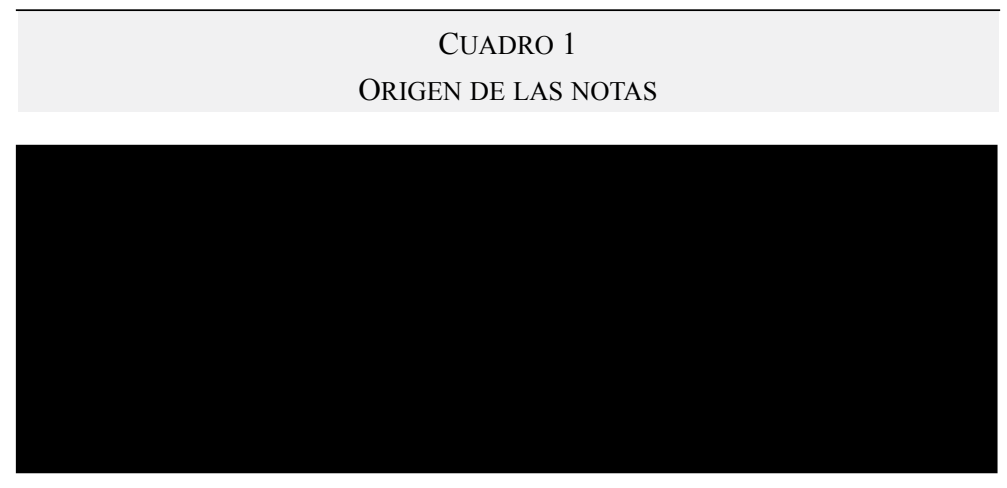

sobre los que reporta, creando frases y metáforas que emanan de la cultura popular y que los periodistas comparten con el público (idem). En este contexto es relevante prestar atención a las narrativas que aparecen en la prensa, pues nos indican las formas en que los individuos construyen su visión del mundo.

$\mathrm{Al}$ respecto, dar seguimiento a los marcos con que el periódico $E l$ Mexicano ha cubierto la interacción entre Tijuana y San Diego resulta sumamente útil, pues retrata construcciones culturales de la relación con los vecinos norteños, que circulan en el discurso público. En la interpretación de los marcos, tienen mucho peso tanto el estudio de temas específicos recurrentes en el contenido periodístico como la orientación de las notas. Al respecto, el contenido de El Mexicano refleja nítidamente la fuerte ambivalencia que existe en cuanto a la relación con Estados Unidos. Por un lado, destacan las notas enfocadas en aspectos negativos de la relación bilateral, que transmiten el sentimiento antinorteamericano y reportan abusos a connacionales. Por otro lado, también se enfatiza la cooperación entre los dos países.

Durante los años sesenta se encontraron noticias sobre festividades binacionales, de cooperación y desarrollo en beneficio de la frontera. En el número de 1968 que revisamos, aparecieron noticias sobre una serie de reuniones que sostuvieron los dos gobiernos para llegar a acuerdos sobre el desarrollo fronterizo. Asimismo, en el ejemplar de 1970 apareció una noticia sobre la participación del Estado mexicano en una junta que se realizó en San Diego para analizar el tráfico de drogas. 
Tiempo después, a mediados de la década de 1960, se hizo más frecuente la aparición de notas que reportaban los problemas sociales que acarreaba el fenómeno migratorio, y la violencia en la frontera se convirtió en un componente importante del contenido periodístico que analizamos. En 1973 apareció en la nota roja: “A balazos y golpes le impidieron pasar a Estados Unidos. Un aspirante a bracero fue agredido por 5 sujetos al tratar de pasar la cerca e ingresar a Estados Unidos" El contenido de esta nota contrasta con las noticias anteriores, que resaltaban la cooperación y amistad entre las dos naciones.

En los ejemplares que revisamos comenzaron a aparecer, hacia mediados de los años 80 , notas que abordaban los problemas que enfrentan los mexicanos en Estados Unidos, como el abuso por parte de las autoridades estadounidenses, el reforzamiento de la vigilancia en la frontera y la severidad de las leyes migratorias. Asimismo, a partir del ejemplar correspondiente a 1986, comenzaron a encontrarse más noticias sobre la problemática de la migración indocumentada. En ese año se publicó una nota sobre el apoyo que brinda México a los "ilegales". Tres años después, en 1989, apareció un encabezado en la primera página de la sección internacional que decía "3 millones de migrantes explotados en Estados Unidos". En este caso, destaca la palabra "explotados", que enfatiza el carácter de víctimas de los migrantes, en contraste con la connotación de criminalidad con que la prensa norteamericana ha tratado la migración. Palabras como "agredido, explotado", y "condenado a muerte" se relacionan frecuentemente con los migrantes indocumentados.

Dos años después, en 1997, se identificaron varias notas que trataban sobre la migración y la doble nacionalidad, un mexicano condenado a muerte, una noticia sobre acciones para evitar el cruce ilegal de la frontera y el reforzamiento de la vigilancia en la línea fronteriza. Finalmente, cabe destacar que, en el ejemplar correspondiente a 2003, comenzaron a encontrarse notas relativas a las remesas que envían los migrantes a México, coincidiendo con los ajustes a las políticas migratorias de ambos gobiernos, mismas que acompañaron el cambio de siglo (Fernández de Castro, 2002.) Es para entonces que comienza a cambiar la imagen de los migrantes, de "víctimas" a "proveedores", a medida que ambos países cobraron conciencia de la importancia económica de estos envíos de dinero. 


\section{LA DIMENSIÓN TRANSFRONTERIZA: PUBLICIDAD Y CLASIFICADOS}

El consumo refleja los elementos más esenciales de la vida cotidiana de la gente y conecta a los individuos con fenómenos que van más allá del mundo privado de cada hogar (Fraser, 1992.) Lo que consumimos nos da un sentido de distinción y también refleja las redes que nos conectan con circuitos nacionales y transnacionales en los que los medios tienen mucho que ver (Castells, 1998; Graham, 2001.) Por estas razones, es notable que, en el caso de la publicidad, se perciba una presencia más significativa de San Diego en lo se refiere a las noticias. Esto indica, entre otras cosas, que el consumo de productos que se venden en las tiendas de San Diego es un hábito arraigado entre los pobladores de Tijuana y que el mercado tijuanense es atractivo para los comercios de California.

La publicidad proveniente de San Diego representa 6.7\% del total. Principalmente se promueven tiendas de ropa y zapatos, supermercados, jugueterías, subastas de autos y objetos usados, joyerías y, en ocasiones, la cartelera cinematográfica. Aun cuando el porcentaje de publicidad proveniente de San Diego es bajo comparado con el de Tijuana (83.84\%), es sobresaliente que, después de los negocios locales, son establecimientos de San Diego los que tienen mayor presencia en la publicidad de El Mexicano. A diferencia de las noticias, el número de anuncios provenientes de San Diego excede a los del resto de México (3.7\%) y otras partes de Estados Unidos (5.3\%) (ver cuadro 2). En más de la mitad de los ejemplares aparecieron de uno a cinco anuncios procedentes de esta ciudad. En nueve ejemplares (19.6\%) aparecieron más de seis avisos. Asimismo, se encontró que la cantidad de anuncios publicitarios de San Diego es directamente proporcional al total que aparece en cada ejemplar, lo que indica la inserción de los establecimientos sandieguinos en los vaivenes de la mercadotecnia tijuanense.

En los ejemplares de mediados de los años 80 comenzaron a aparecer grandes anuncios publicitarios de supermercados mexicanos, como Calimax, Comercial Mexicana, Ley y Blanco. Ocupaban toda la página y en ocasiones hasta dos o tres. De manera similar, pero con menos frecuencia y cantidad, surgía publicidad de tiendas estadounidenses como Ralph, Savons y Toys'R Us (ver cuadro 3). En ocasiones se exhibían 


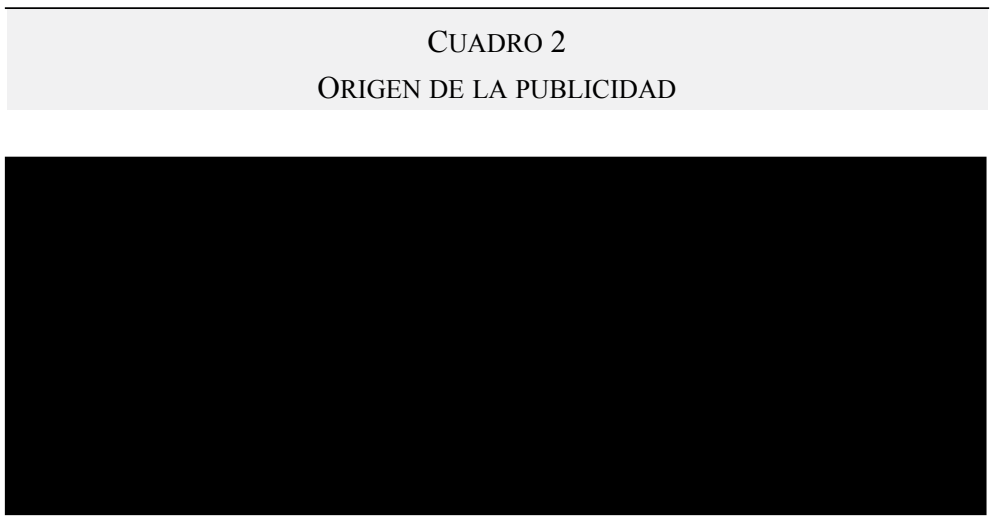

suplementos de tiendas de San Diego, los cuales contenían las ofertas diarias de sus productos. Sin embargo, cuando aparecía una página completa en donde se anunciaban las ofertas de la semana en Savons o Ralphs también se exhibía otro anuncio de Calimax o Comercial Mexicana del mismo tamaño o más grande, en el que mostraban las ofertas de frutas y verduras en las tiendas mexicanas. Paradójicamente, esta guerra comercial parece haber tenido lugar al mismo tiempo que comenzaron a fortalecerse las barreras físicas e institucionales en la frontera, diseñadas por las autoridades federales norteamericanas para detener el flujo de mano de obra indocumentada y el tráfico de drogas, pero que tuvieron un impacto negativo generalizado en la interacción transfronteriza.

De entrevistas que realizamos con mercadólogos de la zona ${ }^{1}$, concluimos que en la disputa por obtener la mayor tajada del mercado tijuanense, los negocios de San Diego cuentan con información sumamente actualizada sobre el poder adquisitivo que tiene la gente de Tijuana, a la cual, por cierto, le da un trato especial. En general, tienen un mejor sistema de ventas y estrategias para acaparar a consumidores

1 Se realizaron entrevistas con expertos en comercio transfronterizo y mercadotecnia, en las que se obtuvo información sobre la investigación de mercado que llevan a cabo los negocios de San Diego entre la población tijuanense, así como los mecanismos para evaluar el éxito de sus campañas publicitarias y estrategias de mercado. 


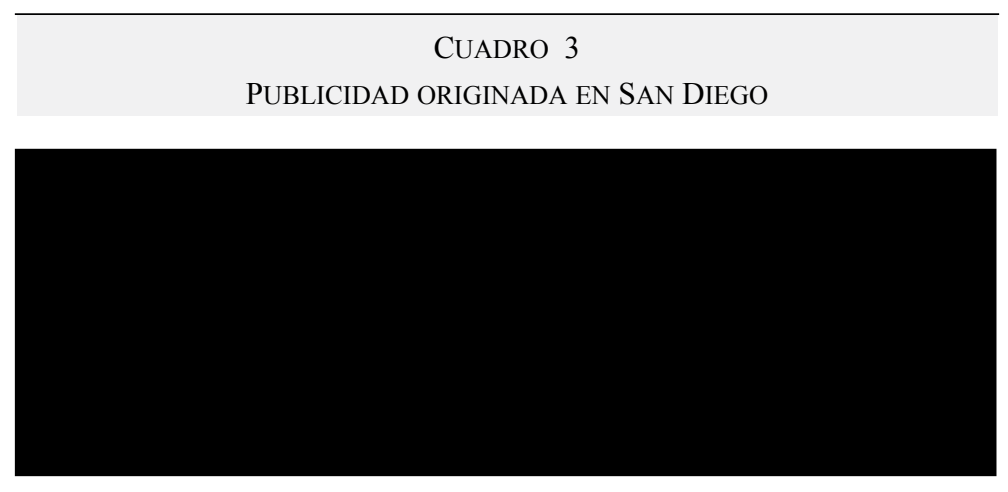

de las dos fronteras y cuentan con políticas de servicio al cliente mejores que las que pueden ofrecer los negocios de Tijuana (Sierra, 2002:705.) Otro punto importante es que los productos ofrecidos en tiendas tijuanenses son, en su mayoría, de origen estadounidense; debido a los costos de importación, resultan más caros que en Estados Unidos. Además, en este país aparecen más rápido, por ejemplo, los nuevos modelos de sistemas electrónicos, lo cual lleva a los consumidores a buscar las novedades en el lado norte de la línea divisoria. Todo ello coloca a los negocios sandieguinos en una posición de ventaja con respecto a los comerciantes tijuanenses, quienes, por otro lado, se benefician de las políticas migratorias norteamericanas y las largas colas que obstaculizan de forma creciente el paso transfronterizo.

En lo que corresponde a los clasificados, se encontró que en 50\% del total de ejemplares aparecieron más de 200 anuncios. En las primeras emisiones del diario aparecían entre 30 y 50 aproximadamente y, con el paso de los años esta cantidad se fue incrementando hasta rebasar los 900. Para estudiar estos avisos se procedió a dividirlos en cuatro categorías de acuerdo a su origen: Tijuana, San Diego, ambas ciudades, otros (ver cuadro 4).

En su mayoría, los clasificados originados en San Diego anuncian empleos que se ofrecen en esa ciudad. También publicitan servicios varios como venta de autos usados, casas en renta o personas que buscan comunicarse con gente de Tijuana. Los clasificados de San Diego representan $0.71 \%$ del total de este tipo de avisos. Aparecieron clasificados de esta 


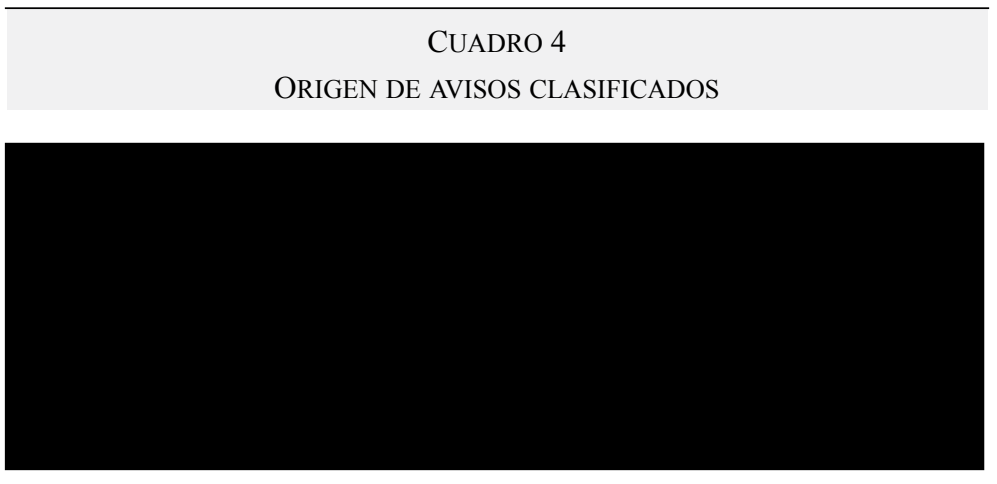

ciudad en casi la mitad del total de casos revisados, mayoritariamente en cantidades de entre 1 y 5 , y nunca excedieron más de 15 anuncios por ejemplar. Ello indica que, a diferencia de los anuncios publicitarios que aumentan de cantidad conforme crece su total, los clasificados que anuncian transacciones relacionadas con San Diego aparecen de forma independiente y se mantienen constantes sin importar las fluctuaciones en el número de anuncios de esta sección (ver cuadro 5).

Los anuncios que aporta San Diego a la sección de clasificados son pocos, pero no irrelevantes. De todos los ejemplares se encontraron en total 85 avisos clasificados originados en San Diego. En los primeros años predominaban los anuncios de empleos de trabajo doméstico. Por ejemplo, un aviso clasificado aparecido en el ejemplar de 1969 decía lo siguiente: "Solicito sirvienta con experiencia para casa. 50 dólares por mes. Escribir a señora Consuelo Castro, 300, norte de Los Ángeles, St. Gen Del". Otro anuncio similar aparecido el mismo año requería servicios parecidos: "Se solicita jovencita para vivir y trabajar en casa. Huntington Beach, California. No necesita hablar inglés". Los dos ejemplos anteriores muestran que no sólo en la región de San Diego se ofertaban empleos dirigidos al público mexicano, sino que las necesidades eran similares también en ciudades como Los Ángeles.

Con el paso de los años seguimos encontrando anuncios de empleos de este tipo, pero también comenzaron a aparecer en el análisis otros como agente de ventas, maestros o mecánicos. Por ejemplo, en 1974 apareció un aviso que decía: "Urgen damas para eventos publicitarios, 


\section{CUADRO 5}

CLASIFICADOS ORIGINADOS EN SAN DIEGO

\begin{tabular}{lccc} 
& Frequencia & Porcentaje & $\begin{array}{c}\text { Porcentaje } \\
\text { acumulado }\end{array}$ \\
$\begin{array}{l}\text { Ningún } \\
\text { clasificado } \\
1-5\end{array}$ & 24 & 52.2 & 52.2 \\
clasificados & 16 & 34.8 & 87.0 \\
$6-10$ & 5 & 10.9 & 97.8 \\
clasificados & 1 & 2.2 & 100.0 \\
$\begin{array}{l}11-15 \\
\text { clasificados }\end{array}$ & & & \\
Total & 46 & 100.0 & \\
\hline
\end{tabular}

756 sur, Broadway St., Despacho 403, 4to, piso, Los Ángeles, Cal. Sr. Yáñez". Otro similar, de un año después avisaba: "Importante compañía norteamericana ofrece a damas con ambición como directiva de demostradores. 60 a 150 dólares semanales. Escribir a P.O. Box 1123, San Isidro, California \#92073”.

Otros ejemplos de comercios de San Diego que ofrecen sus servicios en los clasificados de Tijuana, son los de objetos usados, muy populares entre la población. En 1977 apareció un anuncio de un lote de autos usados en San Diego en el cual se hablaba español. Durante los dos años siguientes se siguieron mostrando avisos de ventas de segunda: "Venta de equipo nuevo y usado de electricidad" (1978) y "Venta de segunda en San Diego. Lámparas, vitrinas" (1979). También, en 1998 apareció uno de remate de autos en San Diego. En la historia de Tijuana es conocido el éxito de este tipo de comercios, que se desarrollan de forma informal y se anuncian en los clasificados como personas privadas.

Hay que recalcar que $98.45 \%$ del total de anuncios clasificados revisados en el estudio provino de Tijuana. Lo que más aparecieron fueron de empleos, rentas (de locales, oficinas y casas) y venta de autos. A diferencia de los anuncios relacionados con San Diego, los clasificados de Tijuana no se enfocan en la ciudad vecina. Casi todos los avisos se 
centran en las necesidades propias de la urbe. Sin embargo sí se encontraron clasificados que hacían referencia a los requerimientos de gente que constantemente visitaba Estados Unidos, que residía o trabajaba allí. Un anuncio que ofrecía servicios en Tijuana a mexicanos residentes en Estados Unidos apareció en 1975: "Emigrados. Toda clase de reclamaciones, accidentes de trabajo, automovilísticos, etc. En estado de California, USA. Con firma de abogados americanos. Lic. Ramón Hirales, tel. 5-76-28. Tijuana, Baja California." Otro, que resaltaba las necesidades de muchos tijuanenses, surgió en la primera edición del diario: "Señora que lleva a sus hijos a la escuela de San Diego. Cobro 1.25 dólar por llevarlos de la colonia Federal a la escuela".

En los clasificados de Tijuana aparecieron algunos que necesitaban personas bilingües. En general, estos empleos los anunciaban empresas maquiladoras. Algunos ofrecimientos de trabajo de los que se publicaron en 1991 estaban escritos en inglés. Esta práctica se volvió cada vez más recurrente y, actualmente, es común encontrar clasificados provenientes de empresas maquiladoras escritos totalmente en inglés que solicitan administradores, ingenieros o puestos parecidos. En otros casos, no se trata de empresas maquiladoras sino puestos ejecutivos de nivel medio que requieren de personal bilingüe.

Otros anuncios clasificados y publicitarios que se relacionan con las necesidades de la gente en la frontera fueron colocados por oficiales norteamericanos de Migración retirados, que ofrecían sus servicios para ayudar a obtener la visa o ciudadanía. En 1968 se encontró uno que decía: "Solicitantes de pasaporte. Ofrece servicios de ayuda y consejos. Exofical del consulado americano en Tijuana. Recién jubilado. Chula Vista o San Ysidro. Tel. 428-21-64.” Más adelante continuaron apareciendo avisos similares, de los cuales destaca uno encontrado en el ejemplar de 1995, no como aviso clasificado, sino como anuncio publicitario "Línea informativa para la ciudadanía de E.U. Preguntas y respuestas. 4 dólares el primer minuto 1-900-288-8378".

\section{CONCLUSIONES}

Aunque lejos de ser conclusiva, la información que arroja el análisis de contenido de El Mexicano aporta pautas para abordar la discusión que 
se planteó al principio, acerca de las construcciones y representaciones culturales que se tiene de San Diego en la prensa tijuanense. Dichas pautas pueden guiar, en estudios posteriores, el estudio de la imagen que tienen los tijuanenses sobre su ciudad vecina. En este sentido, puede interpretarse que los cambios de ubicación a los que se ha visto sujeta en esta publicación tijuanense la sección correspondiente a San Diego, refleja la compleja y contradictoria relación entre ambas ciudades y las enormes dificultades para categorizar a una población que puede estar tan cerca y tan lejos como las circunstancias lo provoquen.

Es cierto que existen signos de cooperación gubernamental e institucional, fuertes lazos familiares entre la población que trascienden la línea fronteriza y muchas necesidades compartidas que nos llevarían a ubicar a San Diego y a Tijuana como parte de una misma región. En este tenor, la importancia que tiene San Diego en la vida de los tijuanenses podría justificar, dependiendo del punto de vista, el colocarla incluso en la primera plana y como parte de las noticias locales. Sin embargo, son innegables las contundentes asimetrías y diferencias culturales entre ambos lados de la línea fronteriza, así como el fuerte sentido de "otredad" con que los habitantes de esta región miran a sus vecinos del norte o sur. Estas consideraciones nos llevarían en una dirección opuesta: a ubicar al vecino San Diego dentro de la categoría de "otro país" e incluirlo en la sección internacional, o cualquier otra que lo disocie de Tijuana.

Resulta paradójico que, en una ciudad fronteriza, la presencia del "otro lado" parezca ser tan magra en la prensa. Por lo menos en lo que respecta a las noticias, los resultados de este estudio indican que El Mexicano no ha prestado a lo largo de los años mucha atención a lo que acontece en San Diego. En este análisis no se descartan las características particulares de este medio informativo, y por esta razón se hace necesario continuar el esfuerzo que aquí se presenta en estudios similares de otros periódicos de la zona. En este caso, la falta de noticias procedentes de San Diego refleja poca interacción periodística con esta ciudad, lo que puede sugerir falta de interés por parte del público lector y un diálogo deficiente entre la opinión pública en el devenir cotidiano de la noticia.

También es relevante el hecho de que los marcos que utiliza El Mexicano no se distinguen de los que usan los medios de comunicación del 
centro y sur de México, que en general reproducen la postura gubernamental de tratar a los migrantes como víctimas de los abusos de las autoridades estadounidenses, $\mathrm{y}$, más recientemente, como héroes que envían recursos a México (Muriá, 2005). En este sentido, ni el contacto cotidiano con los estadounidenses ni la cercanía geográfica han incidido para que se incorpore, en este caso, el punto de vista de sus vecinos del norte en el enfoque con que este medio informativo aborda la problemática fronteriza.

Por otro lado, los resultados de este estudio indican que, en lo que se refiere al consumo, la prensa reporta vínculos entre ambas ciudades más fuertes que en lo que toca a las noticias. Ello refleja un escenario en el que los comerciantes de San Diego utilizan a Tijuana como público meta de algunas de sus campañas publicitarias. Anuncian sus comercios y compiten con los negocios mexicanos para que los tijuanenses adquieran sus productos. Lo palpamos en la guerra de publicidad efectuada en los años 80 entre los comerciantes de ambas ciudades, con respecto a los supermercados.

Si la publicidad indica una fuerte relación transfronteriza en materia de consumo, los clasificados indican lo propio, aunque en menor grado, en lo que respecta al empleo y a las transacciones de carácter privado. Aunque sea mínima la presencia de estos avisos con origen en San Diego, resalta el porcentaje de estos que proponen una transacción binacional, en su mayoría relacionada con ofertas de trabajo. También destacan los que ofrecen servicios, como las subastas de autos usados, pues, como se mencionó, San Diego se beneficia del mercado tijuanenses para sus ventas de productos usados.

En Tijuana, la cercanía de San Diego es muy tangible. Desde los puntos elevados de esta ciudad puede verse, en un día claro, un segmento bastante generoso del "otro lado", la silueta del downtown e incluso los letreros de algunas tiendas. Sin embargo, pese a esta cercanía física y al hecho de que la distancia que separa a Tijuana de esta ciudad norteamericana es mucho menor a la que hay con la ciudad de México, el análisis de contenido que aquí se realizó refleja más presencia de la distante capital mexicana en la cobertura de este periódico tijuanense que de los vecinos del lado norte.

No debe ignorarse aquí el carácter fuertemente nacionalista de $E l$ Mexicano, que como ya se mencionó al principio, surgió con el objetivo 
de fortalecer los vínculos del público bajacaliforniano con el resto de México. Sin embargo, es un hecho que esta publicación no tendría lectores entre la población tijuanense si no hubiese construido enfoques y abordado los temas desde marcos y perspectivas que tuviesen resonancia para el público local (Gamson, 1992.)

En trabajos posteriores debe ponderarse la tendencia a consumir otras fuentes de información que contengan un mayor número de noticias procedentes de San Diego, ya sean medios impresos como el San Diego Union Tribune, muy popular entre el público tijuanense, estaciones de radio, canales de televisión o internet. Aunque no se descarta la importancia de publicaciones como la anterior, el consumo de este tipo de medios necesariamente se limita al dominio del idioma inglés y su distribución es de acceso limitado. Además, sabemos por entrevistas con antiguos residentes ${ }^{2}$ que el hábito de adquirir este periódico sandieguino ha predominado especialmente los domingos, día en que se publican los cupones y ofertas de vigencia semanal en las tiendas de San Diego.

Los resultados del análisis de contenido que aquí realizamos nos aportan elementos interesantes para discutir y teorizar acerca de la interacción que existe entre Tijuana y San Diego, dos ciudades adyacentes, separadas por una frontera. Los resultados de este estudio sugieren poco interés por las noticias de San Diego y, pese a la cercanía geográfica con Estados Unidos, la forma de ver y entender los sucesos acontecidos en "el otro lado" es muy similar a la que proyecta la prensa de la ciudad de México. Ello reforzaría los cuestionamientos a la hipótesis de la tercera nación, que como se mencionó, es popular entre círculos de académicos y periodistas.

Sin embargo, los datos que se obtuvieron del análisis de la publicidad también revelan la existencia de vínculos comerciales entre San Diego y Tijuana, sustentados en el hábito cotidiano que tienen los tijuanenses de realizar compras en el "otro lado". Asimismo, los anuncios clasificados indican conexiones entre los mercados de

2 Se realizaron entrevistas exploratorias con algunos antiguos residentes de la zona para obtener información relativa al consumo de medios y productos en ambos lados de la línea fronteriza. 
trabajo de ambas ciudades y otros lazos humanos que se relacionan con actos de la vida cotidiana, como, por ejemplo, el de ir a la escuela. Por los resultados obtenidos en este análisis de El Mexicano, San Diego parece considerarse más como un supermercado enorme que como una ciudad con sucesos importantes; es mayor la cantidad y relevancia de la publicidad emitida sobre sus comercios que sobre los hechos políticos o sociales. En este caso, las ofertas de San Diego parecen ser más trascendentales que las noticias que podrían ser de más interés para sus ciudadanos.

\section{Bibliografía}

AGUAYO, Sergio (1998) Myths and misperceptions. Changing U.S. elite visions of Mexico. México: Center for U.S.- Mexican Studies/El Colegio de México.

ALVAREZ, Robert (1995) "The Mexican-U.S. border: the making of an anthropology of the borderlands". Annual Reviews of Anthropology, vol. 24.

BustamanTE, Jorge (1989) "Frontera México-Estados Unidos. Referencias para un marco teórico", Frontera Norte, vol. 1, núm. 1.

CASTELLS, Manuel (1998) The rise of the network society. EUA:Blackwell.

COATSWORTH, J., y C. Rico (1989) Images of Mexico in the United States. EUA: Center for U.S.-Mexican Studies/ University of California San Diego.

DUARTE, Carlos (2001) "Defining the U.S.-Mexico border as hiperreality”, Estudios Fronterizos, vol. 2, núm. 4.

FÉLIX Berumen, Humberto (2003) Tijuana la horrible. Entre la historia y el mito. México: COLEF/EL DÍA.

FERNÁNDEZ de Castro, Rafael (2002) "La migración sobre la mesa de negociación", en J. Castañeda y R. Fernández de Castro, Cambio y continuidad en la política exterior de México. México: Ariel.

FRASER, Nancy (1992) "Rethinking the public sphere: a contribution to the critique of actually existing democracy". En C. Calhoun, Habermas and the public sphere. Cambridge: MIT PRESS.

GAMSON, William (1992) Talking politics. Inglaterra: Cambridge University Press. 
GRAHAM, S. y S. Marvin (2001) Splintering urbanism. Networked infrastructures, technological mobilities and the urban condition. EUA: Routledge.

HERZOG, Lawrence (1990) Where North meets South. Cities, space and politics on the U.S.-Mexico border. EUA: U.S.-Mexican Studies Center.

MURIÁ, Magalí (2005) "Covering migration and migration policies in Mexico and the United States: perspectives of dialogue in the public sphere", ponencia presentada en el X Congreso de la Asociación Española de Ciencia Política (AECPA) en Madrid.

NEVINS, Joseph (2002) Operation gatekeeper: the rise of the illegal alien and the U.S.-Mexico boundary. EUA: Routledge.

SCHUDSON, Michael (1995) The power of news. EUA: Harvard University Press.

SIERRA LÓPEZ, O. y S. Serrano (2002) "Patrones y hábitos de consumo en Baja California" en Comercio Exterior, vol.52, núm.1.

TIME ( 2001) "Welcome to Amexica", special issue, junio 11.

TRUJILlo Muñoz, Gabriel (2000) La canción del progreso. Vida y milagros del periodismo bajacaliforniano. México: Larva.

WALLIN, Ruth (2003) "Barrier of bridge: Photojournalism of the San Diego-Tijuana border region". En The communication review, vol. 6 , núm. 2. 